Check for updates

Cite this: RSC Adv., 2019, 9, 15246

\title{
Rheological properties of an ultra-high salt hydrophobic associated polymer as a fracturing fluid system $\uparrow$
}

\author{
Jinhao Gao, (D) a Guanghua Zhang, ${ }^{\text {*a }}$ Lei Wang, ${ }^{\mathrm{a}}$ Li Ding, ${ }^{\mathrm{b}}$ Huaqiang Shi, ${ }^{\mathrm{b}}$ Xiaojuan Lai, ${ }^{\mathrm{a}}$ \\ Xin Wen, ${ }^{a}$ Shaoyun $\mathrm{Ma}^{\mathrm{a}}$ and Chuanqing Huang ${ }^{\mathrm{a}}$
}

Herein, a novel ultra-high salt hydrophobic associated polymer, UUCPAM, was prepared using acrylamide, acrylic acid, 2-acrylamide-2-methyl propane sulfonic acid and the hydrophobic monomer UUC. Polymerization exothermic test results indicated that the increase in the hydrophobic monomer content led to an increase in the exothermic time, which is considerably conducive to the formation of hydrophobic structures. The scanning electron microscopy and transmission electron microscopy studies showed that the polymer had complex network structures and that this phenomenon was considerably obvious in $\mathrm{NaCl}$ solution. The fluorescence probe experiment verified that the critical association concentration of this polymer decreased with an increase in the hydrophobic monomer. Rheology studies indicated that the polymer had good temperature and shear resistance in $\mathrm{NaCl}$ solution. Moreover, the apparent viscosity of the polymer remained above $80 \mathrm{mPa} s$ when $0.3 \mathrm{wt} \%$ UUCPAM was added at $170 \mathrm{~s}^{-1}$ in $20000 \mathrm{mg} \mathrm{L}^{-1} \mathrm{NaCl}$ solution at $90{ }^{\circ} \mathrm{C}$. The storage modulus that indicated strong elasticity increased with an increase in the polymer concentration. Meanwhile, the number of hydrophobic micro-zones increased, thus forming dense network structures. Therefore, the polymer was found to have excellent salt resistance and extensive application prospects.

Received 7th March 2019 Accepted 29th April 2019 DOI: 10.1039/c9ra01725a

rsc.li/rsc-advances the separation of molecule monomers, low molecular weight and temperature control. Simultaneously, a chain transfer phenomenon occurs, resulting in a low molecular weight. Moreover, the purification process is relatively complex. To overcome these limitations, researchers have proposed several techniques, including a low temperature for initiation. Currently, polymerization conditions attract considerable attention, such as temperature, monomer content, and length of the hydrophobic chain, which exert a significant effect. The salt tolerance of a polymer is an important factor that restricts its application. Most modified polymers have poor performance in brine..$^{7-10}$

Herein, the preparation conditions of a hydrophobic associated polymer and the basic law of reaction were analyzed. Moreover, the mechanism of the salt tolerance was investigated through microstructure analysis. Fig. 1 shows the mechanism of the rheological properties. This study provides technical support for the application of a hydrophobic associated polymer in tight oil reservoir reconstruction.

\section{Experimental}

\section{Materials}

Analytical grade purity acrylamide (AM), acrylic acid (AA), 2acrylamido-2-methylpropanesulfonic acid (AMPS), ammonium persulfate (APS), ascorbic acid (VC), 2,2'-azo-bis(2methylpropionamide)dihydrochloride (V50) reagents were used 


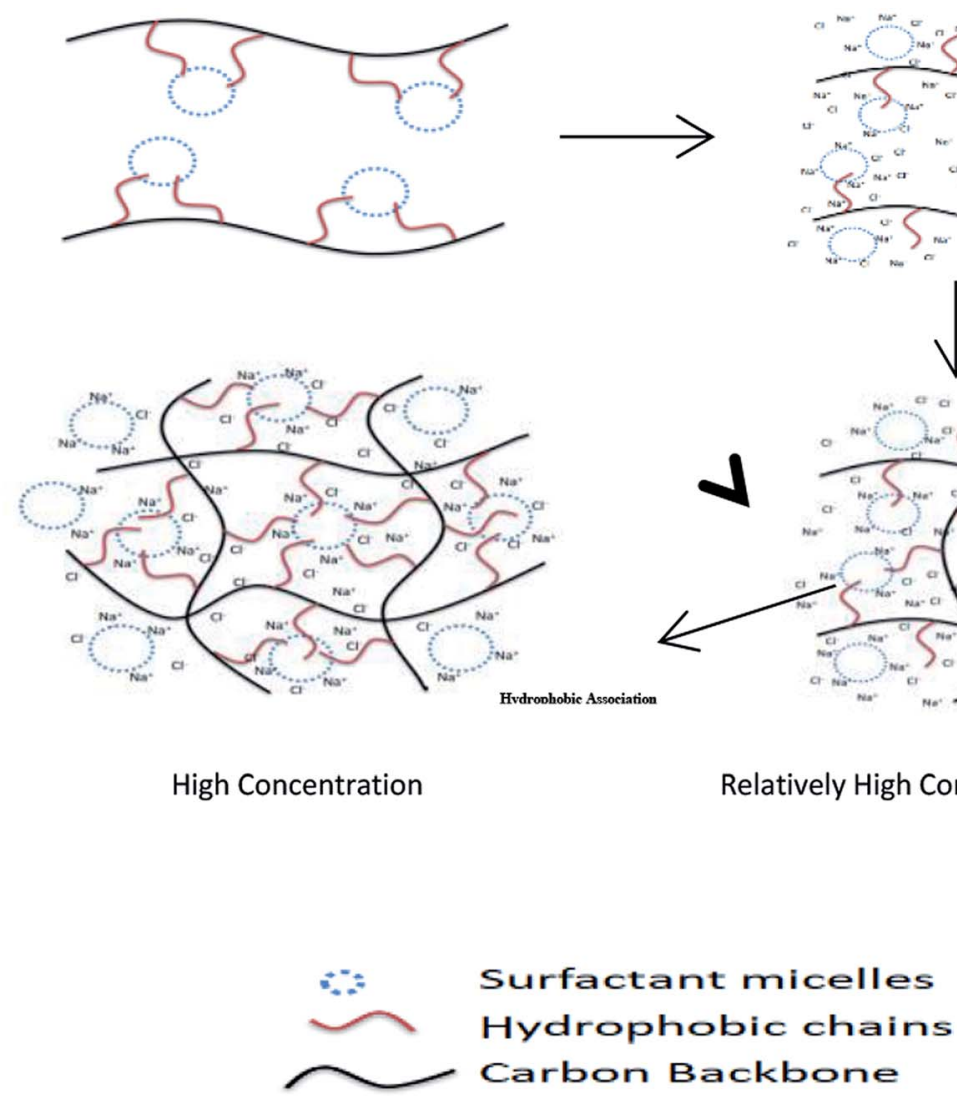

Fig. 1 Mechanism of the ultra-high salt hydrophobic associated polymer UUCPAM.

in the experiments. The hydrophobic monomer (UUC), $\mathrm{NaCl}$ solution $\left(20000 \mathrm{mg} \mathrm{L}^{-1}\right)$, and surfactant (SDS) were made in the laboratory. All chemicals were utilized without further purification.

\section{Synthesis of UUCPAM}

An aqueous solution of the monomer was prepared with a total concentration of $25 \mathrm{wt} \%$ and surfactant SDS content of $7 \%$ of the total monomer concentration. The mass ratio of reactive monomer was $m(\mathrm{AM}): m(\mathrm{AA}): m$ (AMPS) $: m(\mathrm{UUC})=65: 25: 9: 1$. The solution was deoxygenated for $30 \mathrm{~min}$ at $6-8^{\circ} \mathrm{C}$. In the preparation of a $1 \%$ initiator aqueous solution, with a dosage of $0.04 \%$ (based on monomer total mass), the mass ratio was $m(\mathrm{APS}): m(\mathrm{VC}): m(\mathrm{~V} 50)=2: 1: 1$. The reaction was conducted at $90{ }^{\circ} \mathrm{C}$ for $3.0 \mathrm{~h}$ and a colloidal product was obtained. A white powder of the hydrophobic associated polymer UUCPAM was obtained by smashing and drying at $90{ }^{\circ} \mathrm{C}$. The synthesis process is shown in Scheme 1.

\section{Measurements and microstructure}

(i) TEM of UUCPAM. TEM was used to characterize the hydrophobic associated polymer solution microstructure by comparing the difference with an ordinary polyacrylamide aqueous microstructure, providing an analytical basis for the special rheological properties through structural comparison. Polymer solutions were prepared with concentrations of $0.1 \mathrm{wt} \%$, $0.2 \mathrm{wt} \%$ and $0.3 \mathrm{wt} \%$ in a $20000 \mathrm{mg} \mathrm{L}^{-1} \mathrm{NaCl}$ solution. The samples were observed with (JEM-200CX) a transmission electron microscope made by the Japanese Electronics Company after drying on 200 mesh copper wire mesh.

(ii) SEM of UUCPAM. The morphology was investigated using an environmental scanning electron microscope (ESEM, Quanta 450 , USA). A system of $0.3 \mathrm{wt} \%$ UUCPAM that was treated in pure water and a $20000 \mathrm{mg} \mathrm{L}^{-1}$ salt solution for $90 \mathrm{~min}$ at a shear rate of $170 \mathrm{~s}^{-1}$, was prepared and dropped onto glass slides to obtain samples for ESEM observation. All of the samples were dried at room temperature and then frozen using liquid nitrogen. The frozen surfaces of the samples were observed with an ESEM operating at an accelerating voltage of $20 \mathrm{kV}$.

(iii) Measurement of the rheological properties. Rheological measurements were conducted on a HAAKE RS600 rheometer. These measurements were made with a cone. The rheology of UUCPAM solutions with different concentrations (0.1 wt\%,

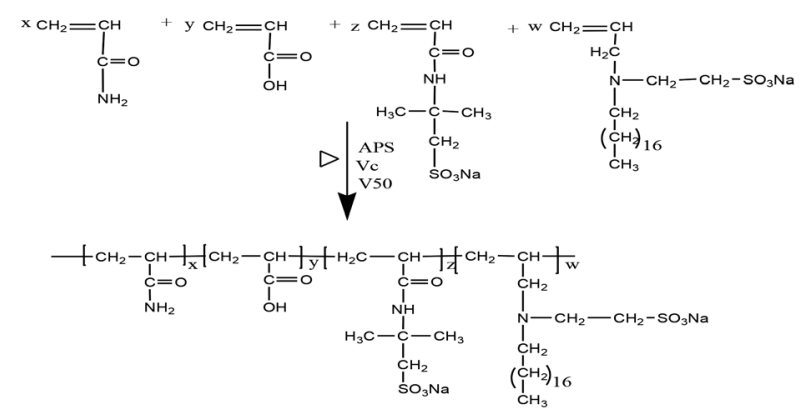

Scheme 1 Synthesis of UUCPAM. 


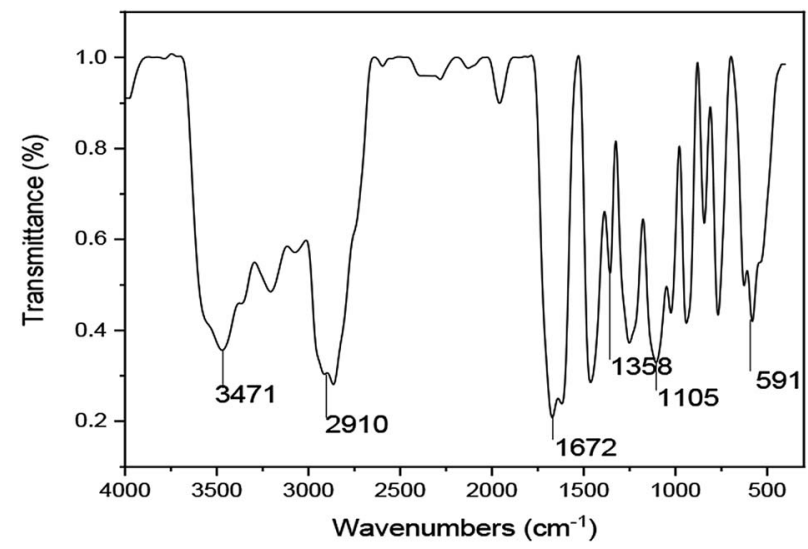

Fig. 2 The FTIR spectrum of UUCPAM.

$0.2 \mathrm{wt} \%, 0.3 \mathrm{wt} \%$ ) were measured over a temperature range of 30 $90{ }^{\circ} \mathrm{C}$ in a $20000 \mathrm{mg} \mathrm{L}^{-1}$ salt solution with a constant shear rate of $170 \mathrm{~s}^{-1}$. Then, the rheology of the UUCPAM solution was measured at a constant temperature of $90{ }^{\circ} \mathrm{C}$ in a $20000 \mathrm{mg} \mathrm{L}^{-1}$ salt solution under a shear rate of $170 \mathrm{~s}^{-1}$.

The detailed experimental procedures can be found in the ESI. $\dagger$

\section{Results and discussion}

\section{Characterization}

(i) IR analysis. Fig. 2 shows the Fourier-transform infrared (FTIR) spectrum of UUCPAM. As can be observed, the peak at $3471 \mathrm{~cm}^{-1}$ is caused by $-\mathrm{N}-\mathrm{H}$ and $\mathrm{O}-\mathrm{H}$, and that at $2910 \mathrm{~cm}^{-1}$ is generated by the antisymmetric vibration of $\mathrm{C}-\mathrm{H}$. The strong absorption peak at $1672 \mathrm{~cm}^{-1}$ is caused by the stretching vibration of $-\mathrm{C}=\mathrm{O}$ in the amide and carboxyl groups. Meanwhile, the peak at $1105 \mathrm{~cm}^{-1}$ is due to the stretching vibrations of $-\mathrm{C}-\mathrm{N}-$ and $-\mathrm{C}-$ C-. Additionally, the absorption peaks at approximately $1358 \mathrm{~cm}^{-1}$ in the IR spectrum are due to the stretching vibrations of the $-\mathrm{SO}_{3}{ }^{2-}$ groups. The absorption peak at $591 \mathrm{~cm}^{-1}$ is caused by $-\left(\mathrm{CH}_{2}\right)_{16^{-}}$in the hydrophobic chains. These results verified that the synthesized polymer was consistent with the designed UUCPAM.

(ii) ${ }^{1} \mathbf{H}$ NMR analysis. The resonances of the protons are shown in Fig. 3, as follows: $4.70\left(\mathrm{D}_{2} \mathrm{O}\right)$ for the solvent peak, 1.57-1.68 ppm (d) and 2.02-2.25 ppm (e) for (- $\left.\mathrm{CH}_{2}-\mathrm{CH}-\right), 1.47 \mathrm{ppm}$ (c) for $\left(-\mathrm{CH}_{3}\right)$ of AMPS, $2.87 \mathrm{ppm}(\mathrm{f})$ for $\left(-\mathrm{CH}_{2}-\right)$ of AMPS and UUC, $3.25 \mathrm{ppm}(\mathrm{g})$ for $\left(-\mathrm{CH}_{2}{ }^{-}\right)$of UUC, $1.21 \mathrm{ppm}$ (b) for $\left(-\mathrm{CH}_{2}{ }^{-}\right)_{16}$ of UUC, $0.85 \mathrm{ppm}$ (a) for $\left(-\mathrm{CH}_{3}\right)$ of UUC, 09-1.12 ppm and 3.55-3.63 ppm for ethanol solvent peaks. The results verified that the synthesized polymer was consistent with the designed UUCPAM.

\section{Microstructure of the hydrophobic associated polymer UUCPAM}

Fig. 4 shows the results of the morphological observation by TEM. The TEM analysis reveals that the hydrophobic associated polymer (UUCPAM) remains in a small bead state in aqueous solution, mainly forming intramolecular associations at low concentration. As shown in Fig. 4(A), the molecular chains are not completely stretched. As the polymer concentration is continuously increased, the intramolecular association becomes relatively noticeable and intermolecular associations are gradually formed, as shown in Fig. 4(B). By increasing the concentration, the associations in the polymer solution are converted from intramolecular to intermolecular. As shown in Fig. 4(C), self-assembly between the macromolecule hydrophobic side chains is evident, forming a dense

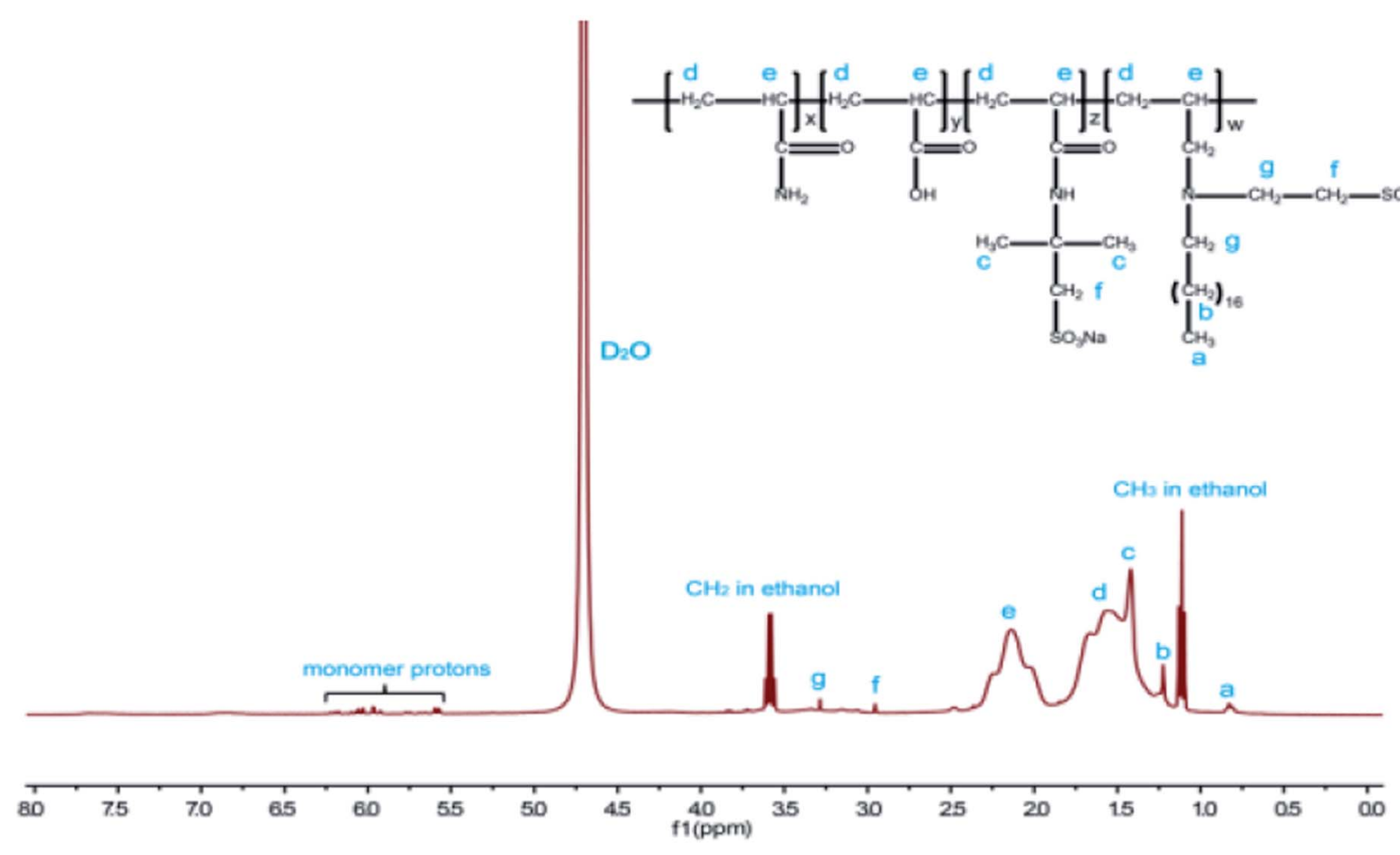

Fig. 3 The ${ }^{1} \mathrm{H}$ NMR spectrum of UUCPAM. 

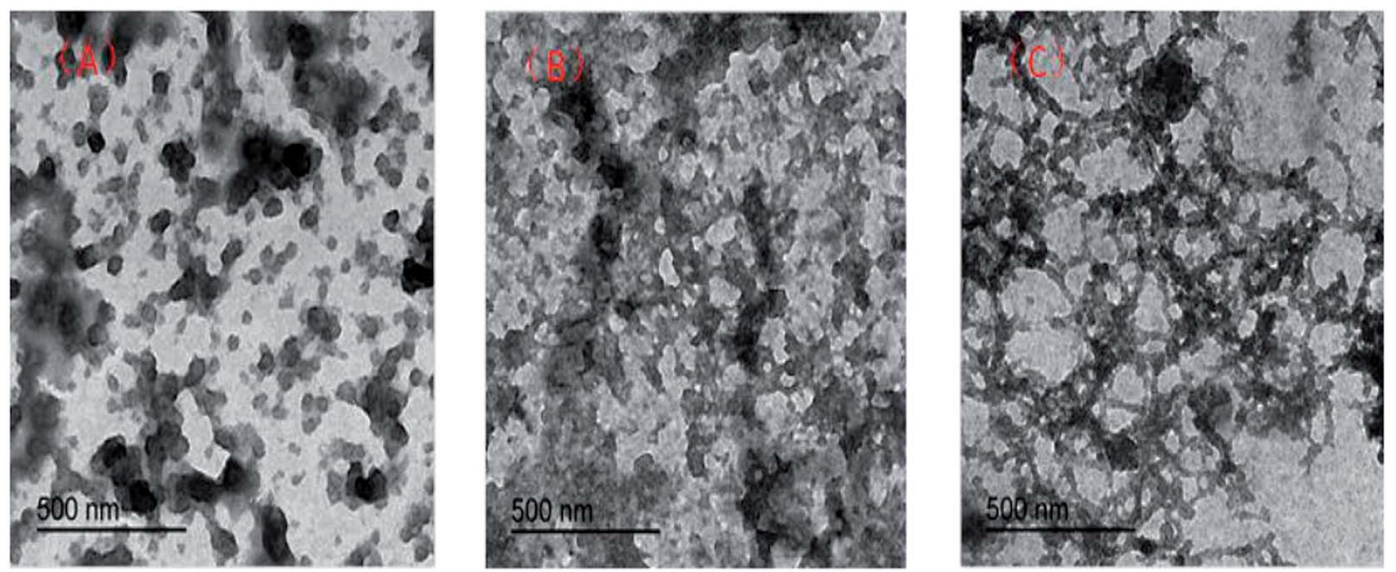

Fig. 4 TEM images of the hydrophobic associated polymer. (A) $0.1 \mathrm{wt} \%$ UUCPAM in $20000 \mathrm{mg} \mathrm{L}^{-1} \mathrm{NaCl}$ salt water, (B) $0.2 \mathrm{wt} \%$ UUCPAM in $20000 \mathrm{mg} \mathrm{L}^{-1} \mathrm{NaCl}$ salt water, and (C) $0.3 \mathrm{wt} \%$ UUCPAM in $20000 \mathrm{mg} \mathrm{L}^{-1} \mathrm{NaCl}$ salt water.

network structure. Moreover, the network structures are observed under CAC conditions.

\section{X-ray diffraction (XRD) of UUCPAM}

$\mathrm{XRD}$ is a technique that can be used to characterize the properties of the polymer. As shown in Fig. 5, the analysis of the XRD pattern suggests that UUCPAM has an amorphous structure. The pattern has no sharp peaks but instead has wide diffuse peaks. Hence, UUCPAM does not absorb outside energy to destroy its spatial crystal lattice, indicating that the polymer can be easily dissolved in water.

\section{Temperature curve of the polymerization process}

The effect of temperature was most noticeable during the synthesis. Common synthesis temperatures of between $40{ }^{\circ} \mathrm{C}$ and $50{ }^{\circ} \mathrm{C}$ were used and an initiator agent was added at high temperature, which is prone to causing implosion. In industrial production, system temperatures tend to be constant or the temperature difference inside and outside of a vessel should not be large. Therefore, a special thermostat is required. Low-temperature initiation and preliminary analysis of its temperature curve at $5{ }^{\circ} \mathrm{C}$ in different hydrophobic monomer concentrations were investigated. As can be observed from the temperature change, the

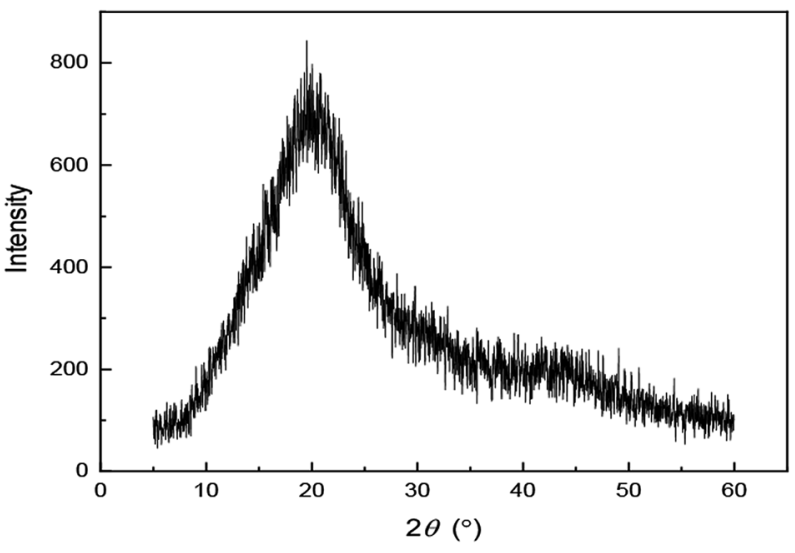

Fig. 5 XRD of the polymer UUCPAM. system response can be commonly divided into three stages. Firstly, acrylamide, acrylic acid, and AMPS molecular chains were opened at low temperature. Secondly, during the heating process, a trace amount of hydrophobic monomer connected to the main chain, forming a macromolecular segment. Thirdly, many hydrophobic monomers successfully connected to the polymer chains, connecting each hydrophobic group with the formed macromolecular chains, resulting in the formation of the desired hydrophobic associated polymer, as shown in Fig. 6(A) and (B).

Fig. 6 shows that the polymerization of the hydrophobic associated polymer can be characterized into stages due to the addition of hydrophobic monomer. The same change in the temperature rate can improve the stability of the initiating system and the polymerization process, so the influence of other factors can be excluded. When the content of hydrophobic monomer is changed, the highest temperature and structure of the polymer solution are affected, as shown in Fig. 6(C) and (D).

The analysis shows that the reaction temperature of the system exhibits some variation with monomer concentration. As the hydrophobic monomer concentration is increased, the released system heat is increased. Reaction auto acceleration is noticeable and the temperature increases. Therefore, the higher the monomer concentration is, the greater the temperature of the reaction end point will be, meaning that the hydrophobic monomer has been grafted in the main chain. When the reaction reaches the highest temperature, the three-dimensional network structure is formed, as shown in Fig. 6(B). As illustrated in Fig. 6(D), more hydrophobic units are formed if the concentration of the hydrophobic monomer is increased. When the concentration of the hydrophobic monomer is low, the numbers of hydrophobic microzones of the polymer are small and the molecular chains are mainly linear, as presented in Fig. 6(C).

\section{The effect of the hydrophobic monomer content on performance}

The intrinsic viscosity and Huggins constant were obtained using the Huggins equation. The intrinsic viscosity, Huggins constant, and polymer concentration can be used to evaluate the dilute solution properties of the polymer. The intrinsic 

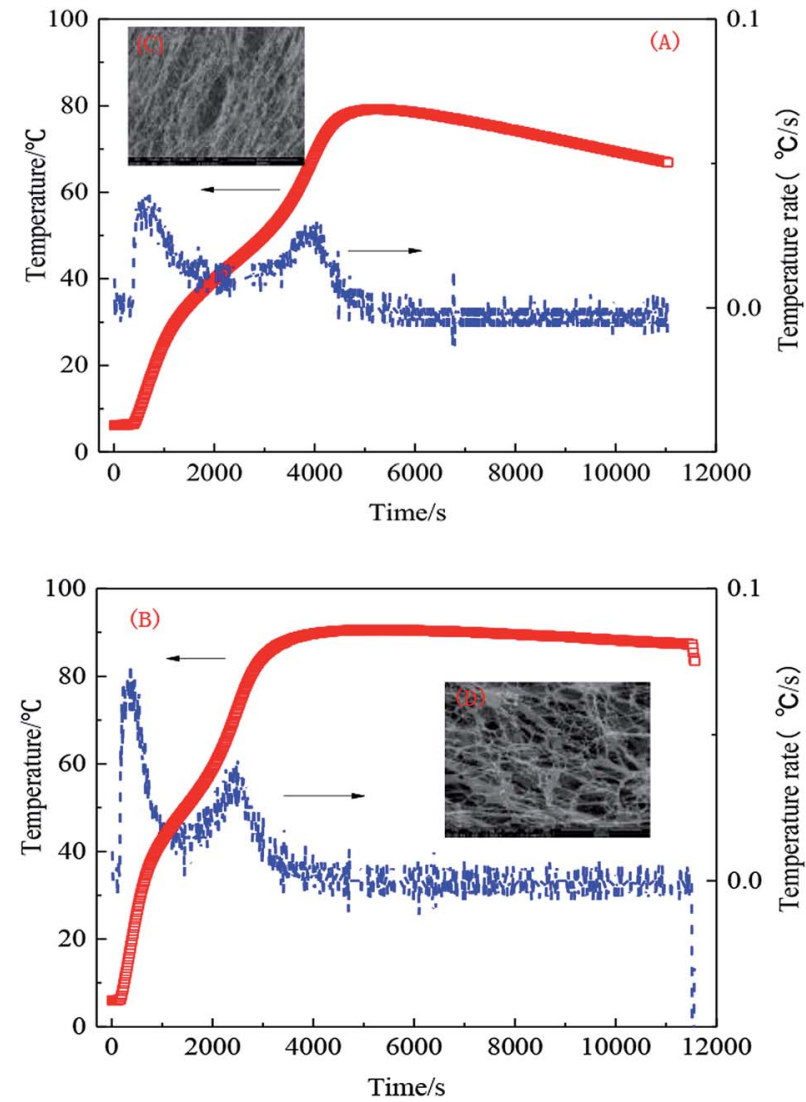

Fig. 6 Polymerization temperature changes with time. (A) $0.5 \mathrm{wt} \%$ UUC and (B) $1.0 \mathrm{wt} \%$ UUC; (C) SEM of sample A with $0.5 \mathrm{wt} \%$ UUC and (D) SEM of sample B with 1.0 wt\% UUC.

viscosity $(\eta)$ and the Huggins constant $\left(K_{\mathrm{H}}\right)$ are influenced by the hydrophobic monomer, as presented in Table 1 . The polymer intrinsic viscosity and Huggins constant show a decreasing trend in pure water and saline upon an increase in hydrophobic monomer concentration. Moreover, the intrinsic viscosity of the polymer in clean water is greater than that in saline. On the contrary, the Huggins constant in saline is greater than that in clean water. ${ }^{11-13}$

At low concentration, the Huggins equation is used to evaluate the intrinsic viscosity and Huggins constant of the solution, which are used to investigate the hydrodynamic volume between polymer

Table 1 Influence of different hydrophobic monomer contents on the polymer properties

\begin{tabular}{|c|c|c|c|c|c|c|c|}
\hline \multirow{2}{*}{$\begin{array}{l}W / \% \\
\text { (UUC) }\end{array}$} & \multicolumn{2}{|c|}{$[\eta] /\left(\mathrm{mL} \mathrm{g}^{-1}\right)$} & \multicolumn{2}{|c|}{$\eta /(\mathrm{mPa} \mathrm{s})$} & \multicolumn{2}{|l|}{$K_{\mathrm{H}}$} & \multirow[b]{2}{*}{ CAC } \\
\hline & Water & Brine & Water & Brine & Water & Brine & \\
\hline 0 & 811 & 730 & 50 & 32 & 0.29 & 0.43 & 0 \\
\hline 0.2 & 733 & 689 & 71 & 80 & 0.77 & 1.06 & 0.81 \\
\hline 0.5 & 623 & 600 & 102 & 84 & 1.13 & 1.34 & 0.70 \\
\hline 0.8 & 553 & 475 & 157 & 102 & 2.21 & 3.01 & 0.57 \\
\hline 1.0 & 575 & 511 & 169 & 115 & 3.75 & 4.18 & 0.32 \\
\hline 1.2 & 527 & 419 & 98 & 62 & 4.24 & 4.63 & 0.58 \\
\hline 1.5 & 450 & 405 & 72 & 40 & 5.12 & 5.47 & 0.64 \\
\hline
\end{tabular}

molecular chains and describe the interaction of different polymer molecular chains. According to eqn (1), the viscosity is tested at different concentrations to determine the intrinsic viscosity and Huggins constant. The equation is expressed as follows:

$$
\frac{\eta_{\mathrm{sp}}}{c}=[\eta]+K_{\mathrm{H}}[\eta]^{2} c,
$$

where $\eta$ denotes the intrinsic viscosity $\left(\mathrm{mL} \mathrm{g}^{-1}\right), K_{\mathrm{H}}$ denotes the Huggins constant, $\eta_{\mathrm{sp}}$ denotes the specific viscosity, and $\eta_{\mathrm{sp}} / c$ denotes the reduced viscosity. $\eta$ and $K_{\mathrm{H}}$ are determined by the linear part calculation of the experimental data obtained through the equation. The hydrophobic monomer in the polymer is a key factor that determines the hydrophobic domain formation. Meanwhile, $\eta$ can be used to express the solution viscosity under infinite dilute condition. This state can be regarded as being approximate to a single molecule. When the hydrophobic monomer content increases, the intramolecular association makes the polymer molecular chain curl up or crinkle, resulting in a low $\eta$ value at the macro level. ${ }^{13-16}$

In dilute solution, the PAM molecule, a type of polyacrylamide, has a spiral or ring structure and the polymer molecular chain stretches. When the hydrophobic group is added into the polymer molecular chain, the hydrophobically modified polymer molecular chain crimps and shrinks, which results in a reduced hydrodynamic volume and decreased apparent viscosity. After the introduction of the long-chain hydrophobic monomer in UUCPAM, intramolecular hydrophobic association also occurs, resulting in a crimped polymer molecular chain. The intramolecular association is enhanced upon an increase in the hydrophobic monomer content. Therefore, the intrinsic viscosity of the UUCPAM polymer will be gradually decreased. The Huggins constant reflects the interaction between the polymer molecular chain and water. As can be observed from the table, the Huggins constant shows an increasing trend with an increase in the hydrophobic monomer content, particularly when the content is changed from 0.8 to $1.5 \mathrm{wt} \%$. This result indicates that the intramolecular association is enhanced with an increase in the hydrophobic chains. In addition, the greater the Huggins constant, the lower the solubility of the polymer. When the hydrophobic monomer content in the experiment reaches $12 \mathrm{wt} \%$, the polymer is difficult to dissolve even after stirring for a long time.

Meanwhile, the apparent viscosity of the polymer is affected by the hydrophobic monomer content in clean water and saline. As the hydrophobic monomer content increases in pure water, the molecular chain stretching is affected and intermolecular association phenomenon occurs, resulting in the increased apparent viscosity of the solution. When the hydrophobic monomer content reaches a certain extent, the distance between the intramolecular hydrophobic groups is reduced, where the intramolecular association is dominant, causing molecular chain curling and a decreasing trend in the viscosity. These reasons can be utilized to explain the influence of the hydrophobic monomer content on the polymer CAC. The lower the CAC of the polymer, the stronger the thickening ability. Therefore, an excessive hydrophobic monomer content adversely affects the polymer solubility and association strength. In addition, after the introduction of the hydrophobic 
group $(0.2 \mathrm{wt} \%)$ into the polymer, the apparent viscosity in saline $\left(20000 \mathrm{mg} \mathrm{L}^{-1}\right)$ is superior than that in pure water. An increase in the hydrophobic monomer amount promotes polymer dissolution and the polarity of the solution increases, which demonstrates an anti-polyelectrolyte effect, so the hydrophobic association is enhanced. Therefore, the salt tolerance performance of the hydrophobic associated polymer is improved, as presented in Table 1.

\section{Effect of the polymer concentration on solution performance}

Pyrene (Py) was employed as a fluorescent probe to perform spectrofluorimetry on the hydrophobic associated polymer. At $25{ }^{\circ} \mathrm{C}$, the pyrene is regarded as a hydrophobic non-polar molecule with considerably low water solubility. Its singlebody spectrum is extremely sensitive to polar environments. A quint of $I$ appears in the fluorescence spectra, the strength of one peak and three peaks shifts with polar environmental change of the solution. Commonly, the $I_{1} / I_{3}$ ratio is used to determine the solvent polarity, which can be used to evaluate the microscopic changes in the solvent environment polarity of polymer molecules. Without the polymer, the hydrophobic microregion is not formed and the environment polarity of the pyrene molecule is strong. The spectral characteristics of this molecule in polar environment are enhanced in $I_{1}$. With polymer addition, a hydrophobic microregion is gradually formed. Owing to its strong hydrophobicity, the Py molecule has the priority to be a part of the formed hydrophobic microregion, showing Py spectral characteristics specific to an oil-soluble environment with an enhanced $I_{3}$. The smaller the $I_{1} / I_{3}$ ratio is, the smaller the polarity environment of Py will be. This result objectively indicates that the more hydrophobic microregions of the intramolecular and intermolecular associations of the hydrophobic associated polymer molecules there are, the greater the hydrodynamic volume and stronger the hydrophobic effect will be. As the hydrophobic monomer content increases at the same concentration, the solution polarity decreases. As shown in Fig. 7, the $I_{1} / I_{3}$ ratio shows a particular variation trend according to the concentration changes of the hydrophobic associated polymer in that its mutational site is basically the same as the CAC. The apparent viscosity of the aqueous solution is increased, in which the $I_{1} / I_{3}$ ratio is rapidly reduced at the same concentration. ${ }^{17-22}$

Fig. 7 the viscosity of the polymer with various hydrophobic monomer content undergoes significant rapid change upon an increase in the concentration, which denotes the critical association concentration. However, such phenomenon of a rapid change in viscosity does not exist for the general category of polyacrylamides that indicated the association occurred. With a polymer concentration of $\mathrm{C}^{\prime} \mathrm{C}^{*}$, there are not large differences in viscosity between the UUCPAM and PAM. UUCPAM mainly demonstrates intramolecular association at low concentrations, resulting in the curling of the polymer coil, hydrodynamic volume reduction and minimal apparent viscosity of the solution. With a concentration of $\mathrm{C}_{>} \mathrm{C}^{*}$, the viscosity of the polymer increases rapidly because intermolecular associations form to produce a super-molecular structure. With the improved

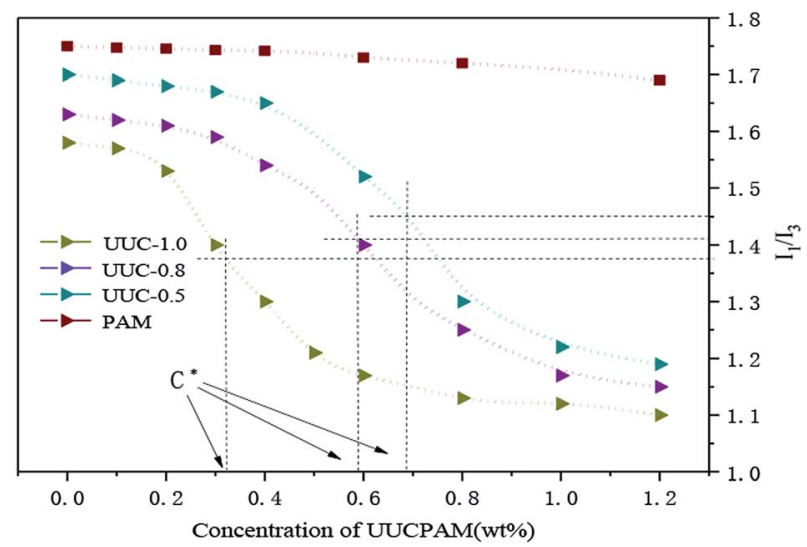

Fig. 7 Performance changes in the $I_{1} / I_{3}$ ratios of aqueous solutions under various polymer concentration conditions.

rigidity of the molecular chain, the system elasticity and hydrodynamic volume increase to form a dynamic physical cross-linked structure with a rapid increase in viscosity. The reason for the PAM viscosity increase is that when the polymer concentration increases, the possibility for intermolecular contact and molecular winding density increases. Meanwhile, the hydrophobic monomer content that promotes the association process increases, the viscosity is significantly increased and the CAC tends to decrease at the same time. However, when the concentration is too large, the hydrophobic group of the main chain block-type access increases and the hydrophobic group spacings decrease, rendering the polymer more inclined to form intramolecular associations, which results in a decrease in the viscosity. Therefore, when the hydrophobic monomer concentration is $1.0 \mathrm{wt} \%$, the apparent viscosity of the solution increases. Thus, the variation trends are more noticeable and the CAC $\left(\mathrm{C}^{*}\right)$ decreases, as shown in Fig. 8.

\section{Viscoelasticity change of the UUCPAM}

A solution was prepared using $0.1 / 0.3 \mathrm{wt} \%$ UUCPAM and mixing it with $0.5 \%$ SDS and then the system was placed into an RS600

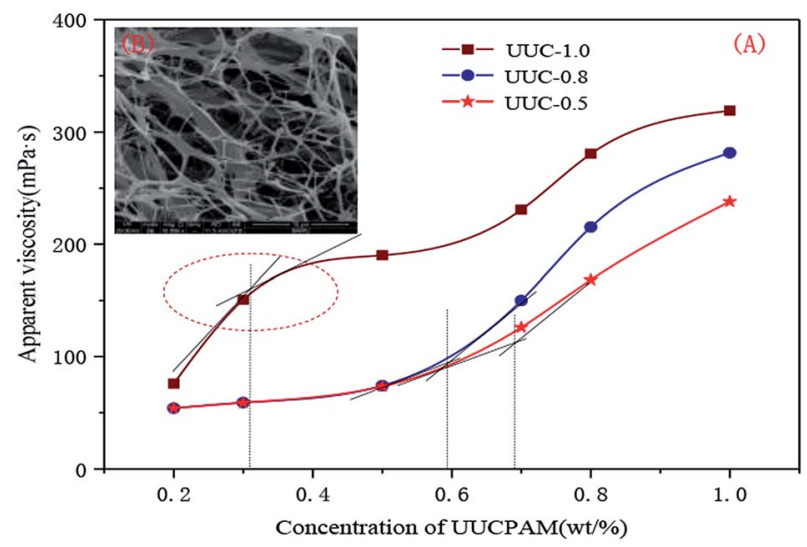

Fig. 8 Apparent viscosity and hydrophobic micro-zone number of the aqueous solution in different polymer concentrations. (A) Apparent viscosity of the UUCPAM and (B) SEM of the UUCPAM under the CAC. 
rheometer at $90{ }^{\circ} \mathrm{C}$ at a shear rate of $170 \mathrm{~s}^{-1}$, as shown in Fig. 11. Fig. 9 shows the results that were obtained through strain scanning experiments at a frequency of $1 \mathrm{~Hz}$. Fig. 10 shows the variation in the storage modulus and loss modulus with frequencies ranging from 0.1 to $10 \mathrm{~Hz}$. The figure shows the polymer viscoelasticity change curve with strain and shear frequency at various concentrations, where $G^{\prime}$ represents the storage modulus and $G^{\prime \prime}$ denotes the loss modulus. The main reason for the viscoelasticity change in the hydrophobic associated polymer solution is the hydrophobic associations among the molecular chains.

Fig. 9 and 10 show that the strain scanning result is close to that of the frequency scanning result. The strain scanning results indicates that the storage modulus $G^{\prime}$ is less than the loss modulus $G^{\prime \prime}$ at low concentration. At a concentration of $0.3 \mathrm{wt} \%$, the $G^{\prime}$ of the polymer solution is greater than the $G^{\prime \prime}$ and the polymer solutions are transformed from viscous to elastic, as shown in Fig. 9(A). When SDS is added, the polymer molecules combine to form a three-dimensional network structure, where the elasticity is enhanced and $G^{\prime}$ is greater than $G^{\prime \prime}$ (Fig. 9(B)).

As shown in Fig. 10(A), the frequency scanning results indicate that $G^{\prime}$ is less than $G^{\prime \prime}$ with a frequency change at $0.1 \mathrm{wt} \%$.
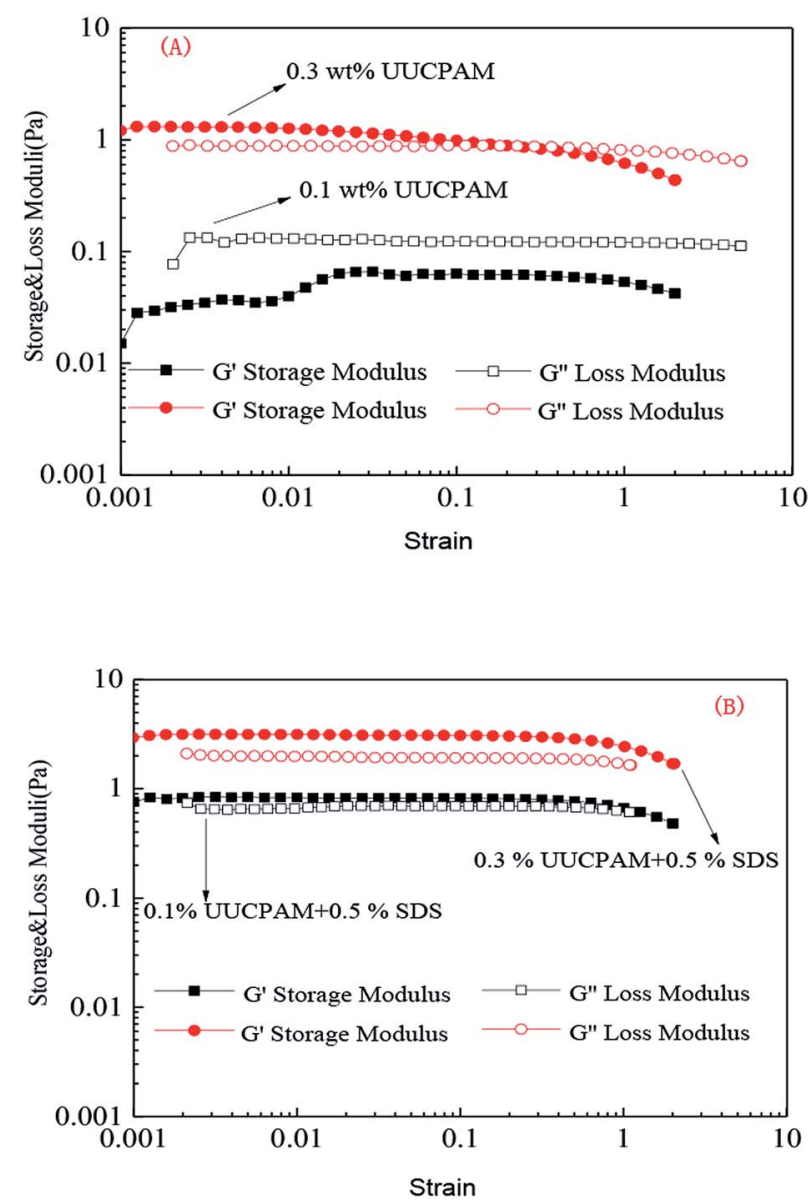

Fig. 9 Strain changes in the polymer viscoelasticity of different UUCPAM concentrations. (A) UUCPAM in $20000 \mathrm{mg} \mathrm{L}^{-1} \mathrm{NaCl}$ solution and (B) UUCPAM + SDS in $20000 \mathrm{mg} \mathrm{L}^{-1} \mathrm{NaCl}$ solution.
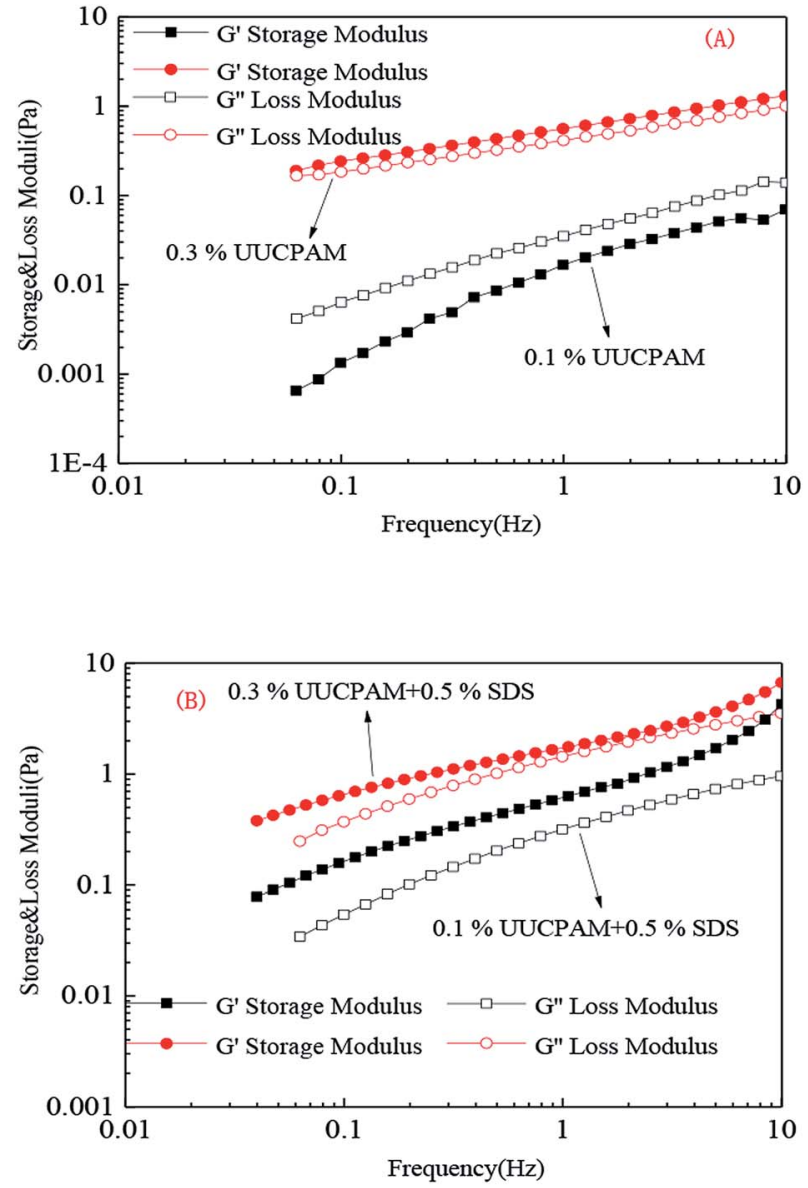

Fig. 10 Frequency changes in the polymer viscoelasticity in various UUCPAM concentrations. (A) UUCPAM in $20000 \mathrm{mg} \mathrm{L}^{-1} \mathrm{NaCl}$ salt solution and (B) UUCPAM + SDS in $20000 \mathrm{mg} \mathrm{L}^{-1} \mathrm{NaCl}$ salt solution.

At this point, the solution is mainly viscous and the molecular chain at low concentration can be completely stretched. Viscosity is generated by the friction between macromolecular chains. When the concentration is increased to $0.3 \mathrm{wt} \%, G^{\prime}$ becomes greater than $G^{\prime \prime}$, as shown in Fig. 10(B).

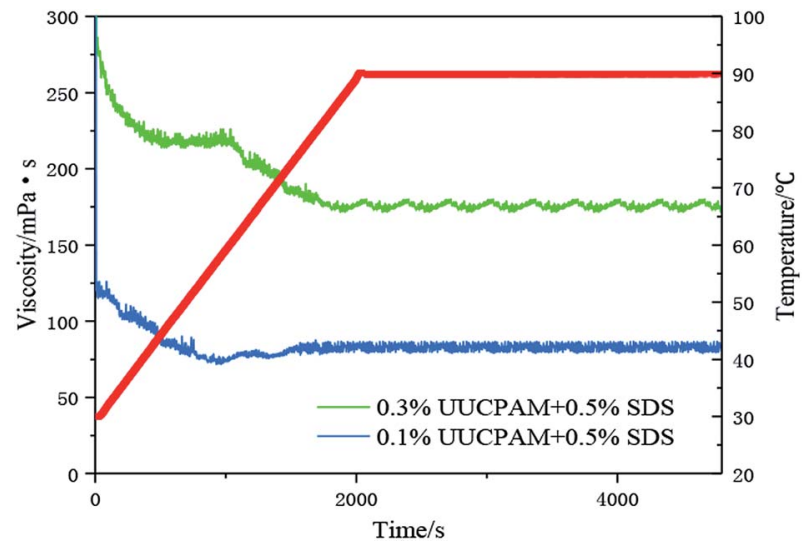

Fig. 11 Rheological properties of the different concentrations of UUCPAM with SDS. 


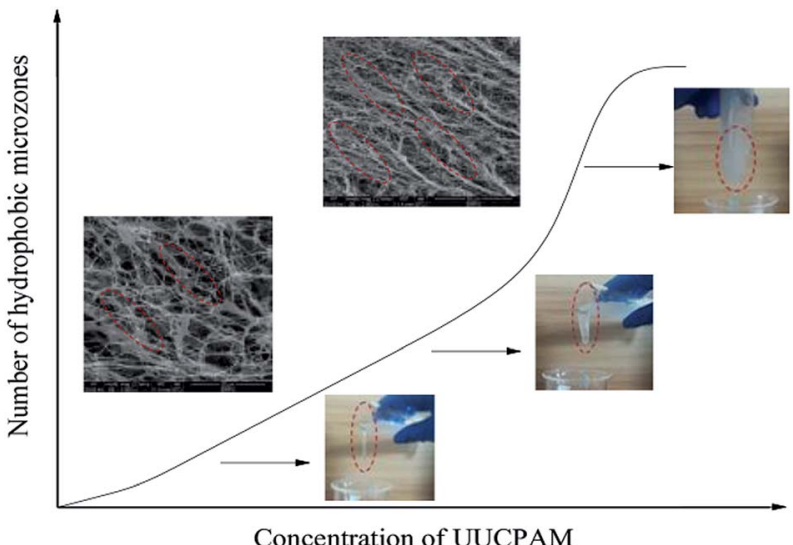

Fig. 12 Changes in the number of hydrophobic micro-zones in pure water.

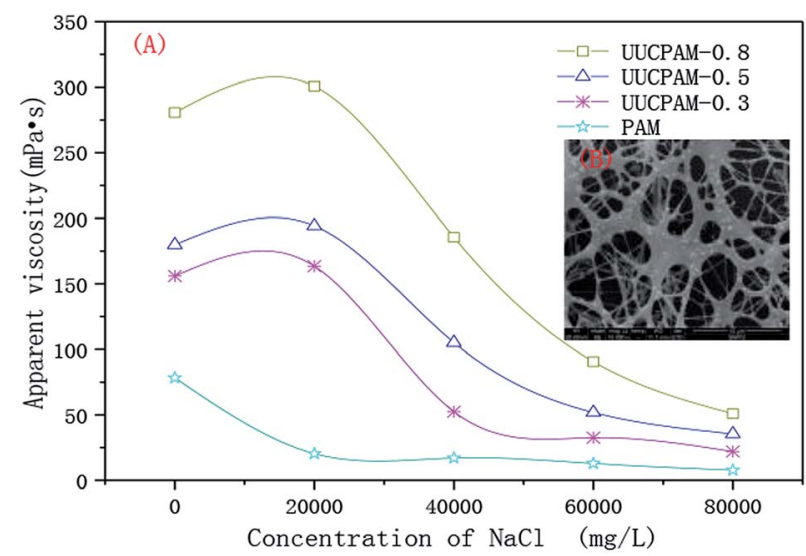

Fig. 13 Effect of the salt on the apparent viscosity of the UUCPAM polymer. (A) Apparent viscosity of UUCPAM in various salt concentrations and (B) SEM of UUCPAM in $20000 \mathrm{mg} \mathrm{L}^{-1} \mathrm{NaCl}$ salt water.

The hydrophobic group of the polymer molecular chain is connected when SDS is added, forming additional network structures. The viscosity of the polymer is also enhanced by the addition of SDS. Free hydrophobic long carbon chains enter the micelles that are formed by the surfactant, as shown in Fig. 11. Fig. 11 shows that the complex viscosity is increased to 170 $\mathrm{mPa} s$ after shearing for a concentration of $0.3 \mathrm{wt} \%$ and 70 $\mathrm{mPa}$ s for $0.1 \mathrm{wt} \%$. This phenomenon also proves that the SDS improves the salt resistance of the polymer. Meanwhile, the number of hydrophobic micro-zones increases when the polymer concentration increases and additional hydrophobic units are obtained, as shown in Fig. 12.

\section{Effect of salt on the rheological properties of the UUCPAM}

An aqueous solution was prepared using $0.3,0.5$, and $0.8 \mathrm{wt} \%$ UUCPAM and the apparent viscosity change was measured with different sodium chloride ( $\mathrm{NaCl}$ ) content. Fig. 13(A) shows that the apparent PAM viscosity rapidly decreased with an increase in the $\mathrm{NaCl}$ content. When the saltiness reached a certain concentration, the viscosity gradually changed. The reason for this is that the addition of salt produces a negatively charged group on the ordinary polyacrylamide backbone shielded by $\mathrm{Na}^{+}$. Mutual repulsion between the charges is reduced and the PAM molecular chains contract, so the apparent viscosity decreases. The apparent viscosity of the UUCPAM solution is influenced by the enhanced polarity and charge shielding.

The hydrophobic chains in the polymer are carried by the surfactant SDS. When the polymer is dissolved in salt solution, the micelles formed by the surfactant SDS shield the salt ions. As shown in Fig. 13(B), the surfactant micelles were compressed by the salt ions. Therefore, the numbers of micelles increased.

Thus, the polymer formed a more compact spatial network structure, showing the characteristics of the supramolecular polymer (Fig. 14(B)). A linear structure was exhibited in purified water, as shown in Fig. 14(A). Meanwhile, at a suitable salt concentration, strong solubilization occurs. The polarity and intermolecular associations of the polymer aqueous solution all increased, forming hydrophobic microzones. Therefore, molecular chains are converted to supermolecular structures, which contributes to an increase in the viscosity. When the salt concentration is considerably high, the anion charge shielding is greater than the polarity enhancing effects of the SDS. The macromolecules are curled
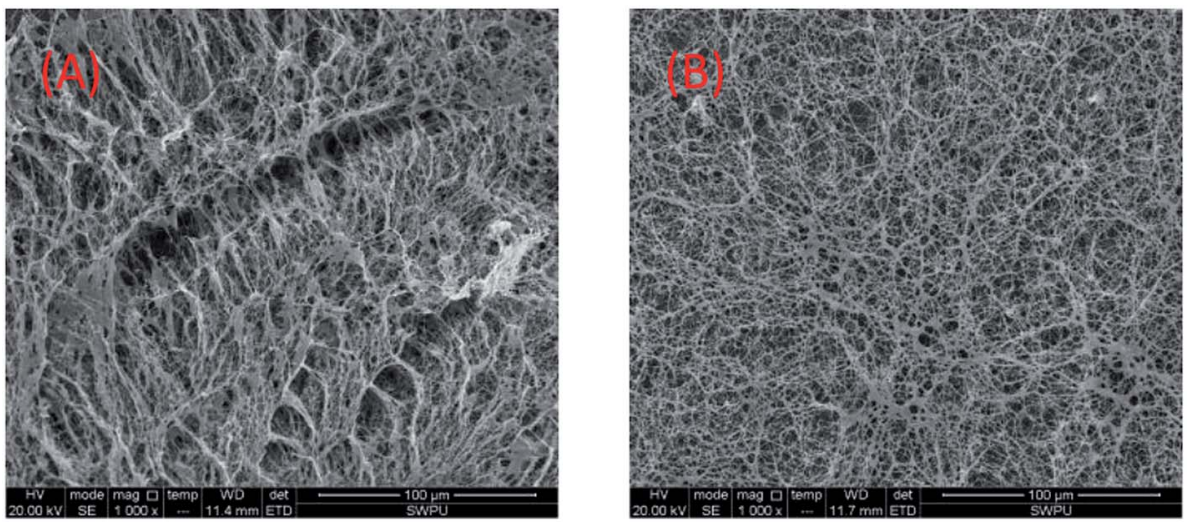

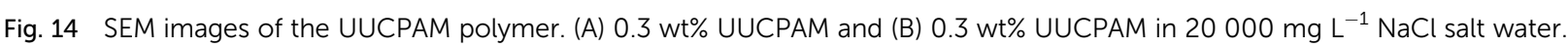



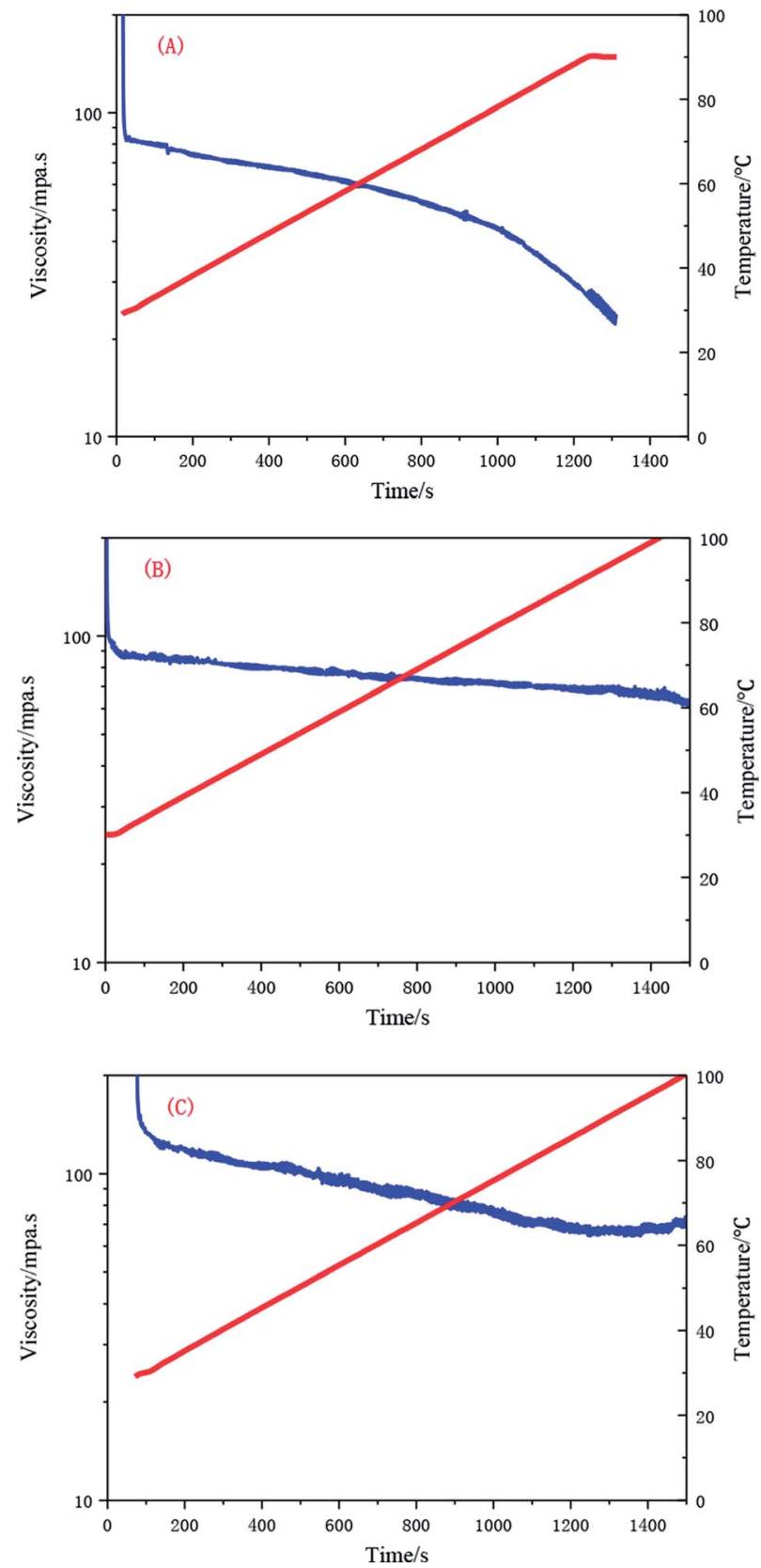

Fig. 15 Effect of temperature on the UUCPAM. (A) $0.1 \mathrm{wt} \%$ UUCPAM in $20000 \mathrm{mg} \mathrm{L}^{-1} \mathrm{NaCl}$ salt water, (B) $0.2 \mathrm{wt} \%$ UUCPAM in $20000 \mathrm{mg} \mathrm{L}^{-1}$ $\mathrm{NaCl}$ salt water, and (C) 0.3 wt\% UUCPAM in $20000 \mathrm{mg} \mathrm{L}^{-1} \mathrm{NaCl}$ salt water.

with most negative charge shielded and the solubility of polymer is decreased. Therefore, the apparent viscosity decreases, as shown in Fig. 13(A). The side group steric hindrance and molecule rigidity are increased by improving the concentration of AMPS. Thus, the salt resistance is improved.

\section{Effect of temperature on the rheological properties of UUCPAM}

When the temperature is raised from 25 to $90{ }^{\circ} \mathrm{C}$, the apparent viscosity of the UUCPAM solution decreases. The viscosity
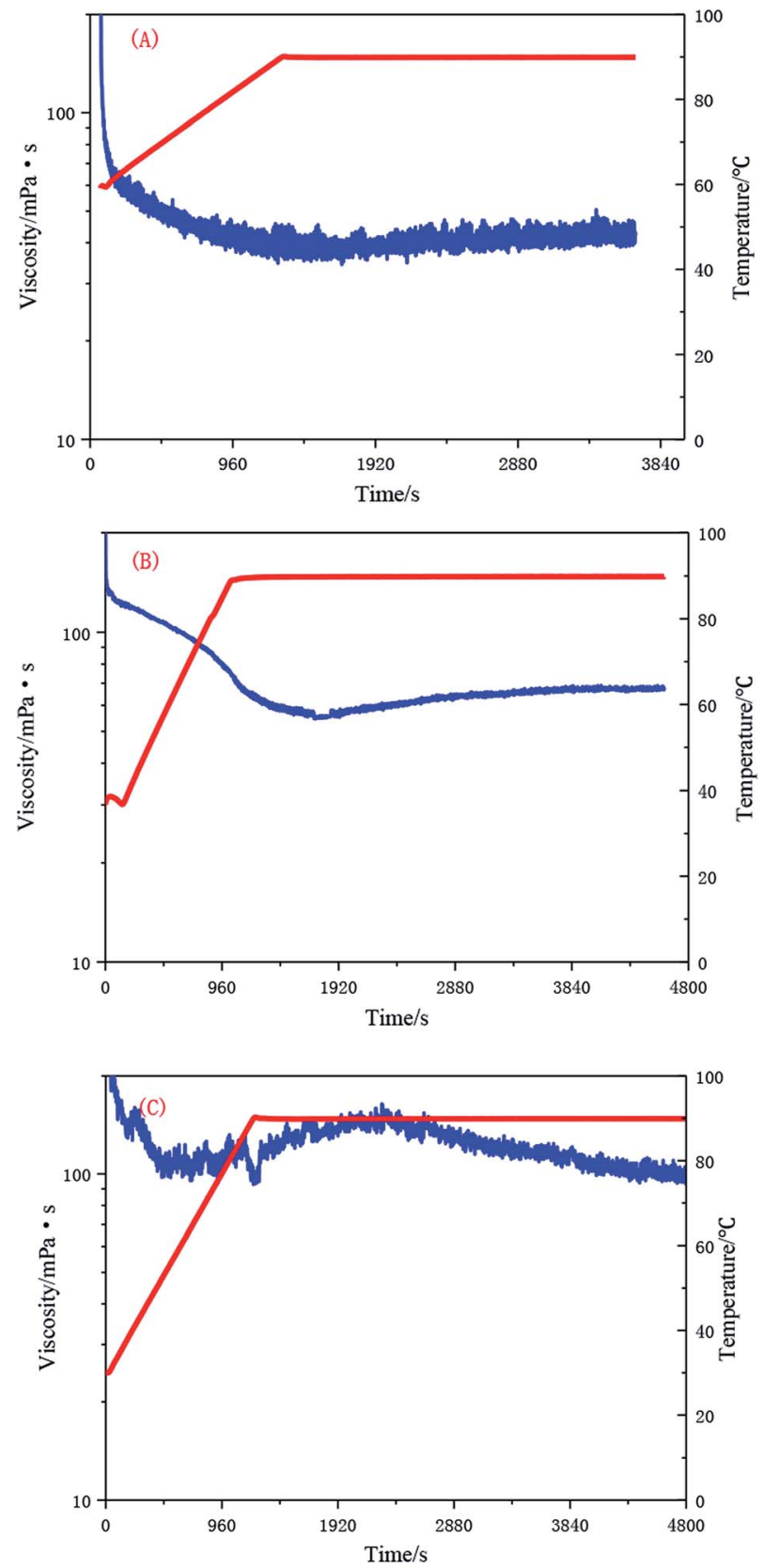

Fig. 16 Effect of the shear rate on the UUCPAM. (A) 0.1 wt\% UUCPAM in $20000 \mathrm{mg} \mathrm{L}^{-1} \mathrm{NaCl}$ water, (B) 0.2 wt\% UUCPAM in $20000 \mathrm{mg} \mathrm{L}^{-1}$ $\mathrm{NaCl}$ salt water, and (C) 0.3 wt\% UUCPAM in $20000 \mathrm{mg} \mathrm{L}^{-1} \mathrm{NaCl}$ salt water.

decreases upon an increase in the temperature at low concentration. However, the temperature resistance of the polymer is enhanced by increasing the concentration. When the polymer concentration is $0.1 \mathrm{wt} \%$, the numbers of hydrophobic microregions are small and the intramolecular association is dominant. The chains of the polymer molecules are stretched with the rise in temperature. ${ }^{23}$ As shown in Fig. 15(A), the viscosity is reduced to $25 \mathrm{mPa} \mathrm{s}$ when the temperature is raised to $90{ }^{\circ} \mathrm{C}$. Moreover, the intramolecular associations gradually transformed to intermolecular associations as the concentration increased, showing a better temperature tolerance. The 
viscosity remained higher than $50 \mathrm{mPa}$, as shown in Fig. 15(B). When the polymer concentration reached the CAC $(0.3 \mathrm{wt} \%)$, the temperature resistance evidently improved, forming a dense network structure. The lowest viscosity was always higher than $70 \mathrm{mPa}$ s, which indicates that the polymer has good temperature tolerance (Fig. 15(C)).

\section{Effect of shear on the rheological properties of UUCPAM}

The test results presented in Fig. 16 show that the UUCPAM polymer has good rheological properties. As the polymer concentration increases, the shear resistance further improves. As shown in Fig. 16(A), the viscosity is higher than $45 \mathrm{mPa} \mathrm{s}$ when the concentration is $0.1 \mathrm{wt} \%$ at $90^{\circ} \mathrm{C}$ at a shear rate of 170 $\mathrm{s}^{-1}$. Meanwhile, the viscosity is higher than $69 \mathrm{mPa} \mathrm{s}$ when the concentration is $0.2 \mathrm{wt} \%$ under the same conditions, as shown in Fig. 16(B). Fig. 16(C) indicates that when the polymer concentration reaches $0.3 \mathrm{wt} \%$, which is the CAC, the viscosity remains higher than $100 \mathrm{mPa} s$ after shearing. In addition, a large number of hydrophobic units interact with each other, forming a dense spatial network structure.

\section{Conclusions}

The anionic hydrophobic monomers UUC and SDS were introduced into a polymer to obtain a high-performance material. The polymer UUCPAM was characterized by FT-IR and ${ }^{1} \mathrm{H}$ NMR spectroscopies. The microstructures of the polymer were observed by TEM and SEM. The rheological properties of the polymer were evaluated and the conclusions are as follows:

(1) The TEM and SEM results indicate that the polymer shows a disorderly network structure in pure water but has a considerably regular arrangement and noticeable spatial network structure in $20000 \mathrm{mg} \mathrm{L}^{-1} \mathrm{NaCl}$ salt water. The solubility and viscosity of the polymer were reduced by increasing the hydrophobic monomer content. Excellent properties were exhibited with $1.0 \mathrm{wt} \%$ UUC. (2) The viscoelasticity tests demonstrated that the $G^{\prime \prime}$ of the aqueous solution was larger than $G^{\prime}$ when the polymer concentration was $0.1 \mathrm{wt} \%$. On the contrary, $G^{\prime}$ was greater than $G^{\prime \prime}$ when the UUCPAM content was increased to $0.3 \mathrm{wt} \%$. However, $G^{\prime}$ was always higher than $G^{\prime \prime}$ regardless of whether the UUCPAM content was 0.1 or $0.3 \mathrm{wt} \%$ when SDS was added. (3) The viscosity changed smoothly at $90{ }^{\circ} \mathrm{C}$ after shearing with the concentration ranging from 0.1 to $0.3 \mathrm{wt} \%$, which showed excellent rheological properties. The viscosity remained higher than $80 \mathrm{mPa}$, particularly when the concentration reached $0.3 \mathrm{wt} \%$. Therefore, the polymer has good salt resistance.

\section{Conflicts of interest}

There are no conflicts of interest.

\section{Acknowledgements}

This research is supported by the Innovative Talents Promotion Plan in Shaanxi Province (2018KJXX-023), the Science and
Technology Program of Xi'an (201805024YD2CG8), the Science and Technology Program of Shaanxi (17JS012), and the Major Program of the National Natural Science Foundation of China (31670596).

\section{Notes and references}

1 A. Cadix, J. Wilson, T. Carouhy, S. Harrisson and H. Guichon, A New Class of Associative Polymer for Hydraulic Fracturing Applications, Society of Petroleum Engineers, 2015.

2 Y. Zhang, J. Mao, J. Zhao, X. Yang, Z. Zhang, B. Yang, W. Zhang and H. Zhang, Chem. Eng. J., 2018, 354, 913-921.

3 L. Qiu, Y. Shen, T. Wang and C. Wang, Rheological and Fracturing Characteristics of a Novel Sulfonated Hydroxypropyl Guar Gum, Int. J. Biol. Macromol., 2018, 117, 974-982.

4 B. Peng, S. Peng, B. Long, Y. Miao and W. Guo, Properties of high-temperature-resistant Drilling Fluids Incorporating Acrylamide/(acrylic acid)/(2-acrylamido-2-methyl-1-propane sulfonic acid) Terpolymer and Aluminum Citrate as Filtration Control Agents, J. Vinyl Add. Tech, 2010, 16, 84-89.

5 C. Wang, L. Qiu and T. Wang, Self-assembly and Rheological Behaviors of Intermacromolecular Complexes Consisting of Oppositely Charged Fluorinated Guar Gums, Carbohydr. Polym., 2018, 184, 333-341.

6 N. El-hoshoudy, S. E. M. Desouky, M. Y. Elkady, A. M. AlSabagh, M. A. Betiha and S. Mahmoud, Hydrophobically Associated Polymers for Wettability Alteration and Enhanced Oil Recovery-Article Review, Egypt. J. Pet., 2017, 26, 757-762.

7 B. Sarsenbekuly, W. Kang, H. Fan, H. Yang, C. Dai, B. Zhao and S. B. Aidarova, Study of Salt Tolerance and Temperature Resistance of a Hydrophobically Modified Polyacrylamide Based Novel Functional Polymer for EOR, Colloids Surf., A, 2017, 514, 91-97.

8 R. Tehrani-Bagha and K. Holmberg, Cationic Estercontaining Gemini Surfactants: Physical-chemical Properties, Langmuir, 2010, 26, 9276-9282.

9 D. Feng, Y. Zhang, Q. Chen, J. Wang, B. Li and Y. Feng, Synthesis and Surface Activities of Amidobetaine Surfactants with Ultra-long Unsaturated Hydrophobic Chains, J. Surfactants Deterg., 2012, 15, 657-661.

10 L. He, The Synthesis of Polymer Gelatinizer and The Rheological Properties of Ultrahigh Temperature Fracturing Fluid System, East China Univ. Sci. Technol, 2013.

11 T. Liu, Y. Yu, Z. Zhao and G. Chen, Synthesis and Performance Evaluation of a Polybetaine Hydrophobically Associating Gelatinizer, Appl. Chem. Ind., 2015, 2, 307-310.

12 C. Yang, Z. Song, J. Zhao, Z. Hua, Y. Zhang and Q. Jiang, Selfassembly Properties of Ultra-long-chain Gemini Surfactants Bearing Multiple Amide Groups with High Performance in Fracturing Fluid Application, Colloids Surf., A, 2017, 523, 62-70.

13 R. Barati and J. Liang, A Review of Fracturing Fluid Systems used for Hydraulic Fracturing of Oil and Gas Wells, J. Appl. Polym. Sci., 2014, 131, 40735. 
14 L. Qiu, Y. Shen, C. Wang and X. Yang, Scanning Electron Microscopy Analysis of Guar Gum in the Dissolution, Gelation and Gel-breaking Process, Polym. Test., 2018, 68, 95-99.

15 F. Chen, Y. Wu, M. Wang and R. Zha, Self-assembly Networks of Wormlike Micelles and Hydrophobically Modified Polyacrylamide with High Performance in Fracturing Fluid Application, Colloid Polym. Sci., 2015, 293, 687-697.

16 Y. Wang, Y. Han, X. Huang, M. Cao and Y. Wang, Aggregation Behaviors of A Series of Anionic Sulfonate Gemini Surfactants and Their Corresponding Monomeric Surfactant, J. Colloid Interface Sci., 2008, 319, 534-541.

17 D. Yu, Y. Wang, J. Zhang, M. Tian, Y. Han and Y. Wang, Effects of Calcium Ions on Solubility and Aggregation Behavior of An Anionic Sulfonate Gemini Surfactant in Aqueous Solutions, J. Colloid Interface Sci., 2012, 381, 83-88.

18 Y. Zhao, X. Chen, B. Jing, X. Wang and F. Ma, Novel Gel Phase Formed by Mixing A Cationic Surfactive Ionic Liquid C16-mimCl and An Anionic Surfactant SDS in Aqueous Solution, J. Phys. Chem. B, 2009, 113, 983-988.
19 Y. Li and J. C. T. Kwak, Rheology of Hydrophobically Modified Polyacrylamide-co-Poly(Acrylic Acid) on Addition of Surfactant and Variation of Solution $\mathrm{pH}$, Langmuir, 2004, 20, 4859-4866.

20 H. Shi, W. Ge, Y. Wang, B. Fang, J. T. Huggins, T. A. Russell, Y. Talmon, D. J. Hart and J. L. Zakin, A Drag Reducing Surfactant Threadlike Micelle System with Unusual Rheological Responses to PH, J. Colloid Interface Sci., 2014, 418, 95-102.

21 K. Lv, L. Zhang and M. Liu, Self-assembly of Triangular Amphiphiles into Diverse Nano/Microstructures and Release Behavior of the Hollow Sphere, Langmuir, 2014, 30, 9295-9302.

22 H. Yang, Z. Ma, B. Yuan, Z. Wang and X. Zhang, Supramolecular Polymerization at The Interface: Layer-byLayer Assembly Driven by Host-Enhanced-Interaction, Chem. Commun., 2014, 50, 11173-11176.

23 H. Fan, Z. Gong, Z. Wei, H. Chen, H. Fan, J. Geng, W. Kang and C. Dai, Understanding the temperature-resistance performance of a borate cross-linked hydroxypropyl guar gum fracturing fluid based on a facile evaluation method, RSC Adv., 2017, 7, 53290-53300. 